\title{
Peptidergic Modulation of Synaptic Transmission in the Parabrachial Nucleus In Vitro: Importance of Degradative Enzymes in Regulating Synaptic Efficacy
}

\author{
Tarek M. Saleh, ${ }^{1}$ Samuel B. Kombian, ${ }^{1}$ Jeffrey A. Zidichouski, ${ }^{1,2}$ and Quentin J. Pittman ${ }^{1}$ \\ ${ }^{1}$ Neuroscience Research Group, University of Calgary, and ${ }^{2}$ Ciba-Geigy Canada Limited, Calgary, \\ Alberta, Canada T2N 4N1
}

This study examined the effects of substance P (SP) and calcitonin gene-related peptide (CGRP) on synaptic transmission in a pontine slice containing the parabrachial nucleus (PBN). Stimulation of the ventral, external lateral portion of the PBN elicited glutamate-mediated EPSCs in cells recorded using the nystatin perforated-patch recording technique in the external lateral, external medial, and central lateral subnuclei of the PBN. Bath application of SP or CGRP dose-dependently and reversibly attenuated the evoked EPSC. The attenuation of the EPSC induced by both of these peptides was not accompanied by changes in input resistance of PBN cells over a wide voltage range, nor did these peptides alter the inward current induced by a brief bath application of AMPA. The combined application of subthreshold concentrations of these peptides revealed a synergistic interaction in reducing the evoked EPSC. The substance $P$ neurokinin-1 receptor antagonist CGP49823 completely and reversibly blocked both the SP- and the CGRP- induced attenuation of the EPSC. However, the rat CGRP receptor antagonist human-CGRP ${ }_{8-37}$ did not block the actions of CGRP or SP on the EPSC. Using a metabolically stable analog of SP, SP(5-11), or an endopeptidase inhibitor, phosphoramidon, we were able to demonstrate that CGRP enhances the SP effect by inhibiting an SP endopeptidase. Application of phosphoramidon also revealed an endogenous SP "tone" apparently made effective by blockade of the endopeptidase. These results suggest that SP (and CGRP indirectly through an inhibition of the SP endopeptidase) acts on presynaptic NK-1 receptors to cause an inhibition of excitatory transmission in the PBN. These results indicate an important role of endopeptidases in regulating synaptic modulation by peptides.

Key words: visceral afferent pathway; CGP49823; synergism; presynaptic modulation; nystatin-patch recording; endopeptidase; phosphoramidon; substance P; calcitonin gene-related peptide
Visceral afferent information is known to reach the CNS via the vagus nerve, which projects to an important brainstem nucleus, the nucleus of the solitary tract (NTS). The NTS, in turn, relays this information via a direct projection to the parabrachial nucleus $(\mathrm{PBN})$, which is also an obligatory synapse between the NTS and the thalamus (Saleh and Cechetto, 1994) in the relay of visceral information destined for the sensory cortex. Although synaptic transmission through the PBN appears to be glutamatergic in nature (Zidichouski and Jhamandas, 1993; Saleh and Cechetto, 1994; Zidichouski et al., 1996), previous work in vivo has also revealed peptidergic modulation of visceral information passing through the PBN en route to the thalamus (Saleh and Cechetto, 1993). In studies involving the microinjection of SP and CGRP into the PBN while recording the vagally evoked neuronal response in the thalamus, both SP and CGRP were shown to act synergistically to inhibit the flow of glutamatergic transmission through the PBN in vivo (Saleh and Cechetto, 1993, 1995). Also, Mantyh and Hunt (1985) demonstrated substance P (SP)- and

Received April 3, 1996; revised June 14, 1996; accepted July 18, 1996.

This work was supported by the Heart and Stroke Foundation of Canada. T.M.S. was supported by postdoctoral fellowships from the Alberta Heritage Foundation for Medical Research (AHFMR), S.B.K. was supported by a Medical Research Council (MRC; Canada) Centennial Fellowship, and Q.J.P. was supported by an MRC and AHFMR Senior Scientist Award. We thank Ciba-Geigy Limited for the generous gift of the NK-1 receptor antagonist and Drs. Brian MacVicar and Morley Hollenberg for their comments on this manuscript.

Correspondence should be addressed to Tarek M. Saleh, Neuroscience Research Group, Faculty of Medicine, University of Calgary, Calgary, Alberta, Canada, T2N 4N1.

Copyright (C) 1996 Society for Neuroscience $\quad$ 0270-6474/96/166046-10\$05.00/0 calcitonin gene-related peptide (CGRP)-immunoreactive fibers and terminals located in nuclei along the visceral afferent pathway. Similarly, binding sites for both of these peptides have been localized to the PBN (SP, Quirion et al., 1983; CGRP, Kruger et al., 1988).

Peptidergic modulation of visceral afferent transmission in the PBN may provide a means for selectively controlling the flow of modality-specific visceral information in the CNS. In fact, immunohistochemical evidence has demonstrated that the intensity of SP and CGRP staining in subnuclei of the PBN is changed significantly in response to loading and unloading of the aortic baroreceptors but not to gastrointestinal stimulation (Saleh and Cechetto, 1996). In light of the critical role of the PBN in controlling the flow of visceral information to higher central areas, as well as a variety of studies pointing to the possible role of this nucleus in modifying response patterns to visceral stimuli (Saleh and Cechetto, 1993), the present investigation was performed to determine directly the electrophysiological effects of SP and CGRP on excitatory synaptic transmission in the PBN. Specifically, we sought to determine the identity of the receptor subtypes involved, whether the site of action was pre- or postsynaptic, and to examine more closely the synergistic action of SP and CGRP using the perforated-patch recording technique in an in vitro slice preparation.

\section{MATERIALS AND METHODS}

Slice preparation. Sprague Dawley rats ( $25-40 \mathrm{~d}$ old) were anesthetized with halothane and decapitated. The brain was quickly removed and 
placed in ice-cold, carbogenated $\left(95 \% \mathrm{CO}_{2} / 5 \% \mathrm{O}_{2}\right)$ artificial CSF (ACSF; $\mathrm{pH} 7.3-7.4)$. Coronal slices (400 $\mu \mathrm{m}$ thick) were cut with a vibratome from a block of tissue containing the parabrachial nucleus, in cold $\left(4^{\circ} \mathrm{C}\right)$, carbogenated ACSF. Pontine slices (bregma -9.1 to $-9.8 \mathrm{~mm}$; Paxinos and Watson, 1986) containing the PBN were then taken and hemisected along the midline and incubated in $\mathrm{ACSF}$ at room temperature $\left(22^{\circ} \mathrm{C}\right)$ for at least $1 \mathrm{hr}$ before recording. A slice was then transferred into a $500 \mu \mathrm{l}$ recording chamber where it was submerged and continuously perfused with prewarmed ACSF $\left(27-29^{\circ} \mathrm{C}\right)$ at a rate of 2-3 $\mathrm{ml} / \mathrm{min}$. The composition of the ACSF was (in mM): $\mathrm{NaCl} 126, \mathrm{KCl} 2.5, \mathrm{NaH}_{2} \mathrm{PO}_{4} 1.2, \mathrm{MgCl}_{2}$ $1.2, \mathrm{CaCl}_{2} 2.4, \mathrm{NaHCO}_{3} 18$, glucose 11 . To evoke synaptic responses, a bipolar stimulating electrode connected to a stimulus isolation unit was placed ventral-lateral to the PBN, close to the ventral tip of the superior cerebellar peduncle. To examine the spontaneous, miniature EPSCs, bath application of sucrose $(30 \mathrm{~mm})$ and TTX $(1 \mu \mathrm{M})$ was used to enhance and isolate spontaneous, presynaptic events (Bekkers and Stevens, 1989).

Nystatin-patch recording. The perforated (nystatin)-patch whole-cell recording technique was used in this study to avoid the problems of "washout" and rundown of responses typically encountered with wholecell patch recording (Blanton et al., 1989; Hamill et al., 1989; Korn and Horn, 1989). The nystatin-patch recording technique has been shown to provide access to the cell and a low signal-to-noise ratio comparable to that observed with whole-cell recording (Korn et al., 1991; Rae et al., 1991; Meriney et al., 1994). Nystatin-patch recordings from PBN neurons were made with glass micropipettes (Garner Glass; tip resistance 4-8 $\mathrm{M} \Omega$ ) filled with a solution containing (in mM): K-acetate 120, HEPES 40, $\mathrm{MgCl}_{2}$ 5, EGTA 10 , and $450 \mu \mathrm{g} / \mathrm{ml}$ nystatin in dimethyl sulfoxide (DMSO) and Pluronic F127. High-resistance seals (1-3 G $\Omega$ ) were made using an Axopatch 2A patch-clamp amplifier in current-clamp mode (Axon Instruments, Foster City, CA). The amplifier was then placed in the voltage-clamp mode and a $-20 \mathrm{mV}$ step (100 msec duration) was applied to monitor the partitioning of nystatin into the membrane. Access to the cell (series resistance 15-25 $\mathrm{M} \Omega$ ) was attained in 1-15 min after seal formation.

Data acquisition and analysis. After attaining access to the cell, the amplifier was switched back to the current-clamp mode and the resting membrane potential was recorded. Action potentials were generated by continuous current injection $(+10$ to $+50 \mathrm{pA})$ and were sampled using pClamp programs (Axon Instruments) to characterize the cells. All cells that satisfied the established criterion of having an action potential amplitude exceeding $90 \mathrm{mV}$ (from peak to trough) were then voltageclamped at $-65 \mathrm{mV}\left(V_{\mathrm{h}}\right)$. All current responses were filtered at 1 or 3 $\mathrm{kHz}$; because currents were small and of slow duration, no compensation for series resistance was done. Synaptic currents were evoked by applying single pulses via bipolar stimulating electrodes ( $\leq 10 \mathrm{~V}, 10-20 \mu \mathrm{sec})$, and a stimulus intensity that yielded a response $50-60 \%$ of the maximum response was used for the remainder of the experiment. Three successive synaptic samples were taken $10 \mathrm{sec}$ apart, digitally averaged, and stored for analysis. In all synaptic current experiments, a $-20 \mathrm{mV}, 50 \mathrm{msec}$ square pulse was applied $100 \mathrm{msec}$ after synaptic stimulation to monitor input and series/access resistance. Current-voltage relationships ( $I-V$ curves) were generated by applying $200 \mathrm{msec}$ step, square voltage pulses from $V_{\mathrm{h}}$ to -120 through to $-20 \mathrm{mV}$ (in $10 \mathrm{mV}$ increments) or by applying slow voltage ramps and recording the corresponding steady-state current. To produce the ramp $I-V$ curve, the voltage was gradually ramped to $-120 \mathrm{mV}$ over a $2 \mathrm{sec}$ period, then ramped (over $\sim 18 \mathrm{sec}$ ) to $-5 \mathrm{mV}$ and then back to $-65 \mathrm{mV}\left(V_{\mathrm{h}}\right)$. In addition to the computerassisted pClamp data acquisition, continuous records of membrane potentials and currents were made on a pen chart recorder (Gould 2400S).

All acquired data were analyzed off-line using pClamp programs and a 386 PC. All data were corrected for any electrode offset observed at the end of each recording session. Input resistances for all cells were estimated from the step $I-V$ protocol by determining the difference of the steady-state current (measured at $\sim 150 \mathrm{msec}$ into the pulse) at -70 and $-50 \mathrm{mV}$. The amplitude of the EPSC was taken as a measure of the magnitude of synaptic strength. Data are expressed either as means of actual currents or as mean percentage change from control values \pm SEM. Cells served as their own controls, and only cells that showed significant recovery $(>85 \%)$ from any drug effect (except in TTX experiments) were included in the analysis. Statistical comparisons were performed on raw data using the Student's $t$ test or one-way ANOVA ( $p \leq$ 0.05 was considered significant).

All drugs were bath-applied by perfusion with ACSF containing the final concentration of the drug. Appropriate stocks were made and diluted with ACSF just before application. Drugs used were 6-cyano-7- nitroquinoxaline-2,3-dione (CNQX), AMPA hydrobromide (both from RBI); SP(5-11), CGRP, and HCGRP (rat CGRP receptor antagonist) (from Bachem); CGP49823 (NK-1; SP receptor antagonist) was a kind gift from Dr. Felix Brugger (Ciba-Geigy Limited); Pluronic F127 was from BASF Wyandotte, and bicuculline, TTX, nystatin, phosphoramidon, and all of the salts in the ACSF were obtained from Sigma (St Louis, MO). Stock solutions of CNQX, AMPA, SP, CGRP, and the NK-1 and $\mathrm{CGRP}$ antagonists were aliquoted and then frozen at $-20^{\circ} \mathrm{C}$.

\section{RESULTS}

All neuronal recordings obtained in this study $(n=79)$ were located in the dorsal, central, and external lateral aspect of the PBN. All cell characteristics recorded in the present study were comparable to those described previously by Zidichouski and Jhamandas (1993). Resting membrane potentials were -53 to $-73 \mathrm{mV}$ (mean $-63 \pm 3.5 \mathrm{mV}$ ), and estimated input resistances were 494-775 $\mathrm{M} \Omega(635 \pm 38 \mathrm{M} \Omega, n=58)$. Stimulus intensitydependent EPSCs could be evoked in $79 \%$ of cells; this EPSC was mediated predominantly by the non-NMDA receptor subtype, because CNQX $(10 \mu \mathrm{M})$ reduced it by $93 \pm 2 \%(n=12)$. All EPSCs were abolished by bath application of TTX $(1 \mu \mathrm{M}$; reduced by $96.5 \pm 0.2 \% ; n=22)$. All experiments were performed in the presence of bicuculline $(25 \mu \mathrm{M})$ to eliminate the possibility of $\mathrm{GABA}_{\mathrm{A}}$-mediated IPSC contamination, even though only glutamate-mediated EPSCs were recorded at $V_{\mathrm{h}}$ because bicuculline $(25 \mu \mathrm{M} ; n=8)$ had little effect on the amplitude of the EPSC (reducing it by $5 \pm 1 \%$ ).

\section{Substance $\mathrm{P}$ - and CGRP-related peptide reduce the amplitude of the EPSC}

In experiments on 19 different cells, bath application of SP $(0.03-10 \mu \mathrm{M})$ in voltage clamp caused a reversible, concentrationdependent decrease in the evoked EPSC with an estimated $\mathrm{EC}_{50}$ of $0.75 \mu \mathrm{M}$ and a maximal effect at $5 \mu \mathrm{M}$ (Fig. 1A1,A2). Figure $1 A 1$ shows a typical example of an EPSC recorded in control and in the presence of $5 \mu \mathrm{M} \mathrm{SP}$ and the recovery after a $10 \mathrm{~min}$ washout. The onset of this effect was observed $\sim 1$ min after application of SP to the bath, with a peak effect observed after 2-3 min. This SP-induced $(10 \mu \mathrm{M})$ blockade of the EPSC was repeatable using multiple applications in the same cell (there was no evidence of desensitization). Similarly, bath application of CGRP (2.5-10 $\mu \mathrm{M} ; n=16)$ in voltage clamp caused a reversible, concentration-dependent decrease in the evoked EPSC with an estimated $\mathrm{EC}_{50}$ of $6.25 \mu \mathrm{M}$ and a maximal effect observed at $10 \mu \mathrm{M}$ (Fig. 1B1,B2). Figure $1 B 1$ shows a typical example of an EPSC recorded in control, in the presence of $10 \mu \mathrm{M}$ CGRP and the recovery after $10 \mathrm{~min}$ washout. The time taken to observe the onset and peak effects was similar to that for SP and, again, there was no evidence of desensitization with multiple application of CGRP.

\section{Attenuation of the EPSC is not postsynaptic}

Under voltage clamp, steady-state $I-V$ curves were generated and showed that those taken in control (TTX only) were superimposable on those taken in the additional presence of SP (1-10 $\mu \mathrm{M})$ or CGRP $(10 \mu \mathrm{M})$ over the voltage ramp tested $(-120$ to $-5 \mathrm{mV}$; $n=6$ for each peptide; data not shown). The possible postsynaptic action of the peptides was also investigated by bath application of AMPA $(2.5 \mu \mathrm{M}$ in TTX for $20 \mathrm{sec})$ alone or in combination with $10 \mu \mathrm{M}$ SP or CGRP. The magnitude of the AMPA response was not changed significantly in the presence of SP (8 \pm $3 \%$ from control; $n=4)$ or CGRP $(6 \pm 2 \%$ from control; $n=4)$. Taken together, these results suggest that the effect of SP on synaptic transmission is not postsynaptically mediated. 

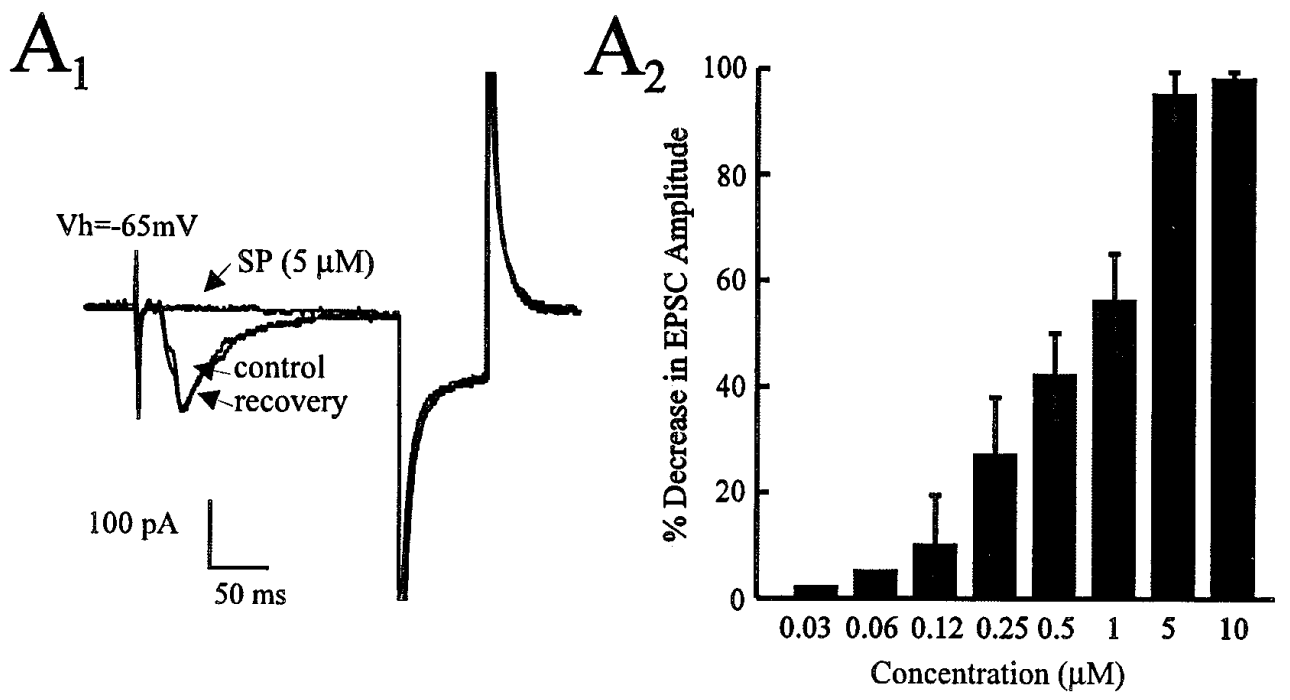

Figure 1. Effects of the peptides substance $\mathrm{P}(S P)$ and calcitonin gene-related peptide $(C G R P)$ on EPSC responses in the PBN. In this and all subsequent figures, stimulus intensities were in the range of $0.2-2.0 \mathrm{~V}$, intensities that yielded EPSC responses $50-60 \%$ of maximum. $A 1$, The synaptic response of a PBN neuron in voltage-clamp experiments $\left(V_{\mathrm{h}}=-65 \mathrm{mV}\right)$. SP $(5 \mu \mathrm{M})$ attenuated the evoked EPSC with no change in input resistance as monitored by a 20 $\mathrm{mV}, 50 \mathrm{msec}$ hyperpolarizing pulse. $A 2$, Dose-dependent attenuations in the EPSC amplitude with an estimated $\mathrm{EC}_{50}$ of $0.75 \mu \mathrm{M}(n=4-9$ cells at each dose $)$. $B 1$, In the same cell $\left(V_{\mathrm{h}}=-65 \mathrm{mV}\right)$, CGRP $(10 \mu \mathrm{M})$ attenuated the EPSC with no change in input resistance as monitored by a $20 \mathrm{mV}, 50 \mathrm{msec}$ hyperpolarizing pulse. $B 2$, Dose-dependent attenuations in the EPSC amplitude with an estimated $\mathrm{EC}_{50}$ of $6.25 \mu \mathrm{M}(n=4-9$ cells at each dose).

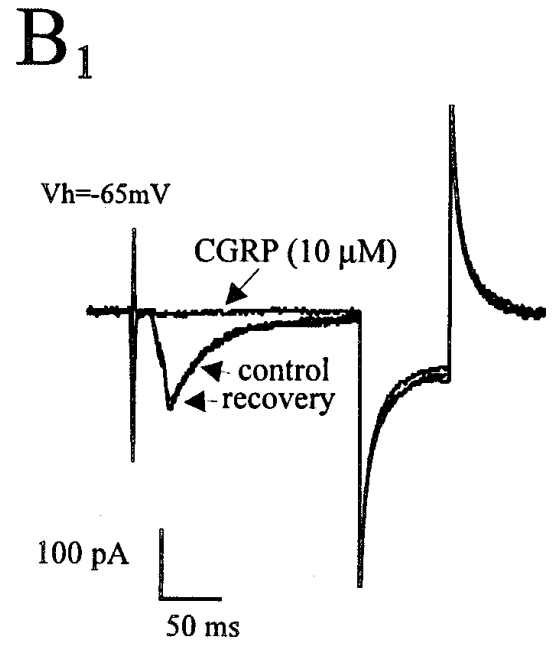

\section{SP and CGRP effects are not polysynaptic}

To rule out possible polysynaptic pathways in the actions of the peptides, we decided to test whether either of these peptides affected the appearance of mEPSCs in voltage clamp. In 4 cells voltage-clamped at $-65 \mathrm{mV}$ and bathed in sucrose $(30 \mathrm{~mm})$ and TTX $(1 \mu \mathrm{M})$ to eliminate action potential-driven EPSCs, bath application of either SP or CGRP reduced, in a reversible manner, the frequency of mEPSCs (by $69 \pm 6$ and $65 \pm 5 \%$, respectively; cutoff $8 \mathrm{pA}$ ). At the end of each experiment, we verified that the mEPSCs were non-NMDA receptor-mediated by completely blocking them with CNQX $(20 \mu \mathrm{M})$.

\section{The CGRP-induced effects on the EPSC are not mediated by a classical CGRP receptor}

To characterize further the CGRP-induced effect on the EPSC, the selective and reversible rat CGRP receptor antagonist HCGRP (Mimeault et al., 1991) was bath-applied in the presence of CGRP. HCGRP $(100 \mu \mathrm{M})$ alone had no effect on the evoked EPSC or on the membrane conductance [Fig. 2 (1)], nor did it block the CGRP-induced $(5 \mu \mathrm{M})$ attenuation of the evoked EPSC $[n=4$; Fig. $2(2,3)]$.
The SP- and CGRP-induced synaptic depression is blocked by the NK-1 receptor antagonist

Because SP has been shown to act at NK-1 receptors, we examined the effect of a selective and reversible NK-1 receptor antagonist, CGP49823 (5-100 $\mu \mathrm{M})$, on the SP-induced attenuation of the EPSC. Bath application of CGP49823 $(n=12)$ alone had no effect on the evoked EPSC or on the membrane conductance because no change in resting current at $V_{\mathrm{h}}$ was observed (data not shown). The SP-induced $(1 \mu \mathrm{M})$ attenuation of the EPSC was completely abolished in the presence of CGP49823 at concentrations of $>20 \mu \mathrm{M}[n=4$ at each concentration; Fig. 3A1-A4 (left), B].

In testing the selectivity of CGP49823 for the SP NK-1 receptor, we examined whether it would affect the CGRP response. Surprisingly, the CGRP (5 $\mu \mathrm{M})$-induced blockade of the EPSC was completely, and reversibly, attenuated by coapplication of CGP49823 at concentrations of $>20 \mu \mathrm{M}[n=4$ at each concentration; Fig. $3 A 1-A 4$ (right), $B]$ in a manner identical to that seen with SP. However, in the converse experiment, application of HCGRP did not significantly change the SP-induced attenuation $(1 \mu \mathrm{M})$ of the EPSC (data not shown). 
1

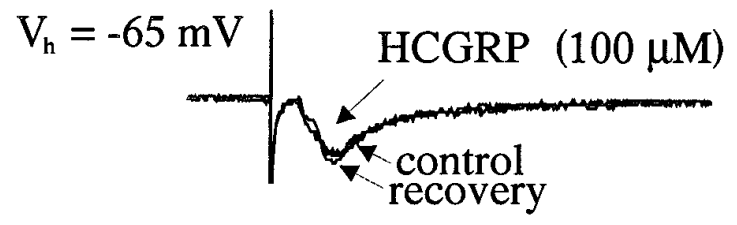

2

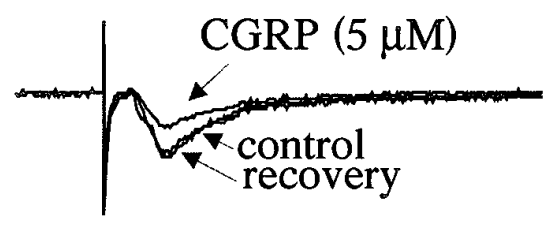

3

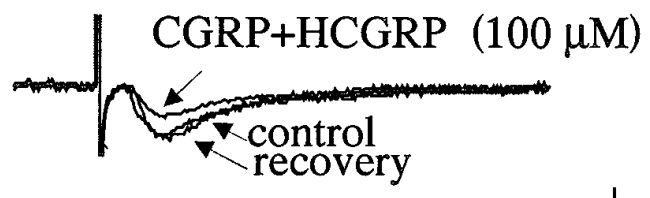

$100 \mathrm{pA}$

$50 \mathrm{~ms}$

Figure 2. Effect of the CGRP receptor antagonist human-CGRP ${ }_{8-37}$ (HCGRP) on CGRP actions. 1, Application of HCGRP alone does not affect the size of the evoked EPSC. 2, The reduction in the amplitude of the EPSC produced by application of an $\mathrm{EC}_{50}$ dose of CGRP $(5 \mu \mathrm{M})$, which is not significantly affected by the CGRP receptor antagonist (HCGRP; $100 \mu \mathrm{M} ; 3)$.

We tested the specificity of the NK-1 receptor antagonist for the NK-1 receptor in blocking the SP- or CGRP-induced decrease of the EPSC. In voltage-clamp experiments $(n=8)$, doseresponse curves for SP and CGRP were generated alone and in the additional presence of the NK-1 receptor antagonist at three concentrations $(10,25$, and $50 \mu \mathrm{M}$; Fig. $4 A 1, B 1)$. In the presence of the NK-1 receptor antagonist, the SP dose-response curves were shifted to the right (Fig. $4 A 1$ ). Using the estimated $\mathrm{ED}_{50}$ of each dose-response curve, we constructed Schild plots for each peptide using the equation $\log (d r-1)=\log [\mathrm{B}]-\log K_{\mathrm{B}}$ (Kenakin, 1987). The slope of the Schild plot is $\sim 1.1$ for SP, which indicates that CGP49823 is a competitive antagonist of the SP NK-1 receptor (Fig. 4A2). In contrast, the slope of the Schild plot constructed for CGRP is $\sim 0.65$, which is significantly different from 1.0; this indicates that CGP49823 may interact in a noncompetitive manner with CGRP at the NK-1 receptor (Fig. 4B2) or that CGRP is acting on a heterogeneous receptor population.

\section{SP and CGRP interaction}

Bath application of a threshold dose of SP $(0.05 \mu \mathrm{M})$ reduced the magnitude of the EPSC by only $5 \pm 2 \%(n=9$; Fig. $5 B, E)$. Similarly, in the same cells, bath application of a threshold concentration of CGRP $(0.1 \mu \mathrm{M})$ reduced the magnitude of the EPSC by only $2 \pm 2 \%(n=9$; Fig. $5 A, E)$. However, coapplication of SP and CGRP at their respective threshold concentrations reduced the amplitude of the EPSC by $27 \pm 9 \%(n=4$; Fig. $5 C, E)$. Furthermore, this synergistic reduction in the EPSC amplitude was reversibly blocked by the NK-1 antagonist CGP49823 [10 $\mu \mathrm{M}$ ( $n=5$; data not shown) or $100 \mu \mathrm{M}(n=4)$; Fig. $5 D]$. In addition, this synergism with a subthreshold concentration of CGRP $(0.1$ $\mu \mathrm{M})$ was observed along the entire dose range of SP used (0.05-10 $\mu \mathrm{M}$; Fig. $5 E ; n=4)$.

An interesting mechanism of interaction for SP and CGRP is suggested by in vitro observations that CGRP competes for the neutral endopeptidase responsible for SP degradation (Le Greves et al., 1985). Therefore, to determine whether this was a possible mechanism for the interaction between SP and CGRP in our study, we used the metabolically stable methylester analog of SP, SP(5-11) (Urban et al., 1994). Bath application of SP(5-11) produced a dose-response curve that had an estimated $\mathrm{ED}_{50}$ of $0.1 \mu \mathrm{M}$ (Fig. $6 A ; \sim 10$-fold more potent than SP; $n=4$ ). This curve, in contrast to the SP dose-response curve, was not affected by the additional presence of CGRP $(0.1 \mu \mathrm{M})$ along the entire concentration range of $\mathrm{SP}(5-11)$ used (Fig. $6 A ; n=4)$.

A second way to test the hypothesis that CGRP was interacting with an SP endopeptidase was to bath-apply a neutral endopeptidase inhibitor, phosphoramidon (10 $\mu \mathrm{M}$; Fig. $6 B)$ (Chiba and Misawa, 1995) to the slice, which reduced the amplitude of the EPSC by $89 \pm 3 \%(n=4$; Fig. $6 B 1)$. The phosphoramidon-induced synaptic depression was blocked by the NK-1 receptor antagonist CGP49823 (100 $\mu \mathrm{M}$; Fig. 6B2; $n=4)$, suggesting a tonic release of SP. Coapplication of CGRP $(0.1 \mu \mathrm{M})$ with phosphoramidon $(10 \mu \mathrm{M})$ did not further enhance the phosphoramidon-induced attenuation of the EPSC ( $n=4$; Fig. $6 B 3, B 4)$. However, when the phosphoramidon concentration was lowered to $5 \mu \mathrm{M}$, the EPSC was attenuated ( $68 \pm 3 \% ; n=4$; Fig. 6B3), and this attenuation in the EPSC was reduced further by CGRP (by $14 \pm 5 \%$; giving a combined attenuation of $82 \pm 5 \%$; Fig. $6 B 3, B 4)$.

\section{DISCUSSION}

The results of this study demonstrate that the peptides SP and CGRP reversibly depress excitatory synaptic transmission in the $\mathrm{PBN}$ in a dose-dependent manner in vitro. The data presented here are consistent with the conclusion that the inhibitory effects of SP occur via presynaptically located NK-1 receptors. The mechanism of the CGRP-induced attenuation of the EPSC appears to be through a novel mechanism involving competition for an SP degrading enzyme, the neutral endopeptidase, to increase the availability of SP.

\section{SP and CGRP act presynaptically to reduce EPSCs}

The dose-dependent, potent actions of SP and CGRP on the evoked EPSC most likely have a presynaptic locus of action. These peptides had no postsynaptic actions on input resistance, on holding current at $-65 \mathrm{mV}$, or on currents generated by a voltage ramp between -120 and $-5 \mathrm{mV}$. An interaction with the postsynaptic AMPA receptors underlying excitatory transmission in the area (Zidichouski et al., 1996) also appears unlikely, because currents elicited by exogenously applied AMPA were unaffected in the presence of maximal concentrations of the peptides. Thus, although we cannot rule out additional postsynaptic actions, evidence supports a presynaptic locus. This is consistent with observations in other brain areas of a presynaptic action of SP (Shapiro and Hille, 1993; Len et al., 1994; Tremblay et al., 1994) and CGRP (Schworer et al., 1991; Nuki et al., 1994). Additional anatomical evidence supporting a presynaptic action would be the localization 
$A_{1}$
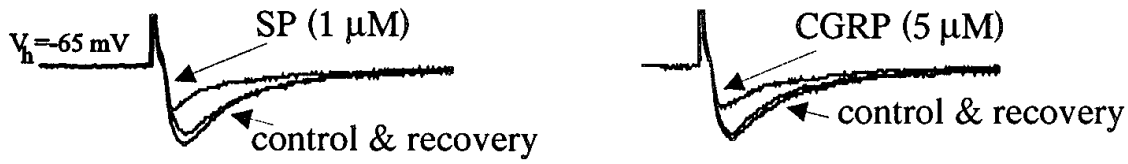

2
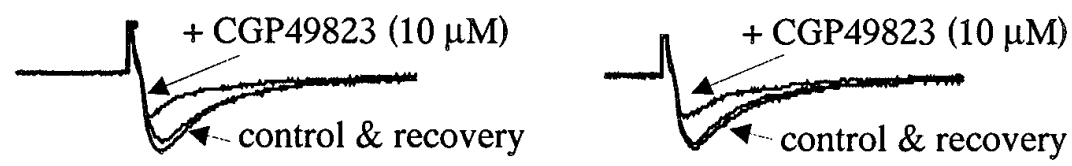

3
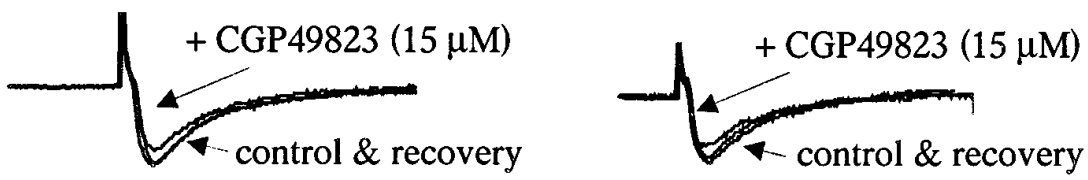

4

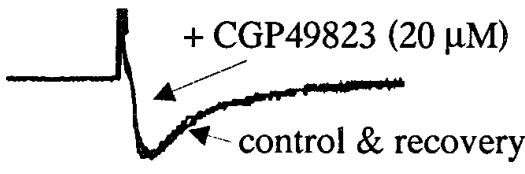

B

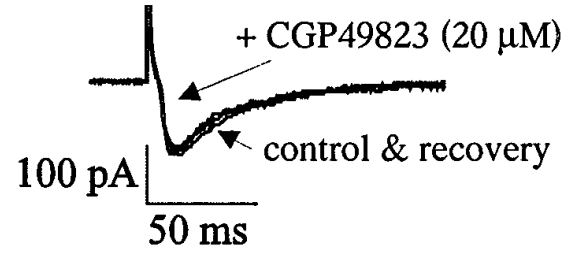

Figure 3. Blockade of SP- and CGRPinduced synaptic depression with the NK-1 receptor antagonist CGP49823. CGP49823 attenuated and, at higher concentrations, blocked the inhibition of the evoked EPSC induced by SP $(1 \mu \mathrm{M}$, left $)$ and CGRP $(5 \mu \mathrm{M}, r i g h t)$ in the same cell $(A 1-A 4, B)$. Application of CGP49823 (5$100 \mu \mathrm{M})$ alone had no observable effect on the EPSC (data not shown). $B$, A graph illustrating that the inhibitory effects of SP $(1 \mu \mathrm{M})$ or CGRP $(5 \mu \mathrm{M})$ are blocked in an identical manner by CGP49823 at all concentrations used ( $n=4$ at each concentration for each peptide). Bars represent mean \pm SEM.

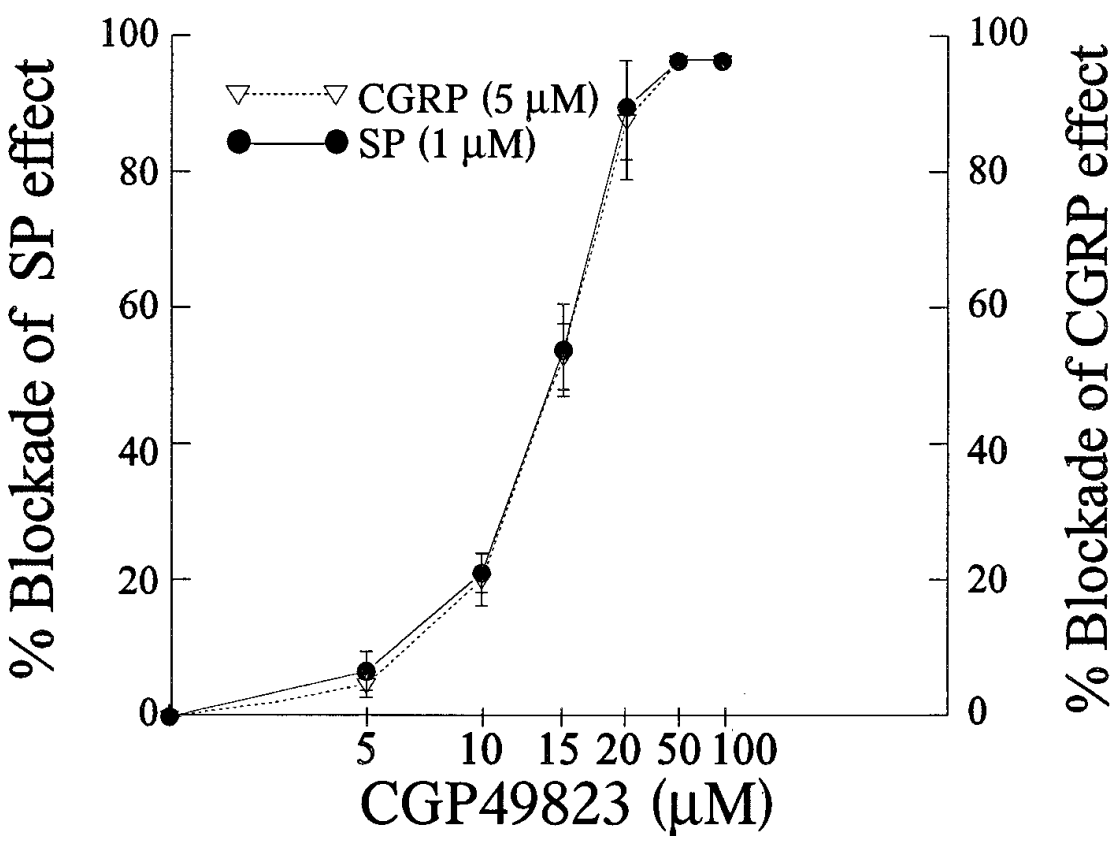

of receptors on presynaptic terminals in the PBN; although autoradiographic studies have identified receptors for both SP (Quirion et al., 1983) and CGRP (Kruger et al., 1988) in the PBN, the cellular locus for them has not been identified. Such a localization on a presynaptic terminal would also eliminate the possibility that these peptides are acting on interneurons that, via release of another transmitter, presynaptically inhibit glutamate release from the excitatory afferents activated in this experiment. However, it is unlikely that there is a GABAergic intermediary because bath application of $\operatorname{SP}(5 \mu \mathrm{M})$ caused an equal attenuation in the size of the EPSC as that reported in this paper, even in the additional presence of the $\mathrm{GABA}_{\mathrm{B}}$ receptor antagonist CGP36742 (data not shown).

\section{Do SP and CGRP act at the same receptor?}

Dose-response studies of the peptide effects on the EPSC revealed classical sigmoid-shaped curves for both peptides. It was interesting that the $\mathrm{EC}_{50}$ for SP was $\sim 10$-fold lower than that for CGRP, raising the possibility that the CGRP has a much lower affinity for its receptor than does SP. To investigate more thoroughly the receptors mediating the effects on the EPSC, we used receptor antagonists to block the peptide actions. SP is thought to 

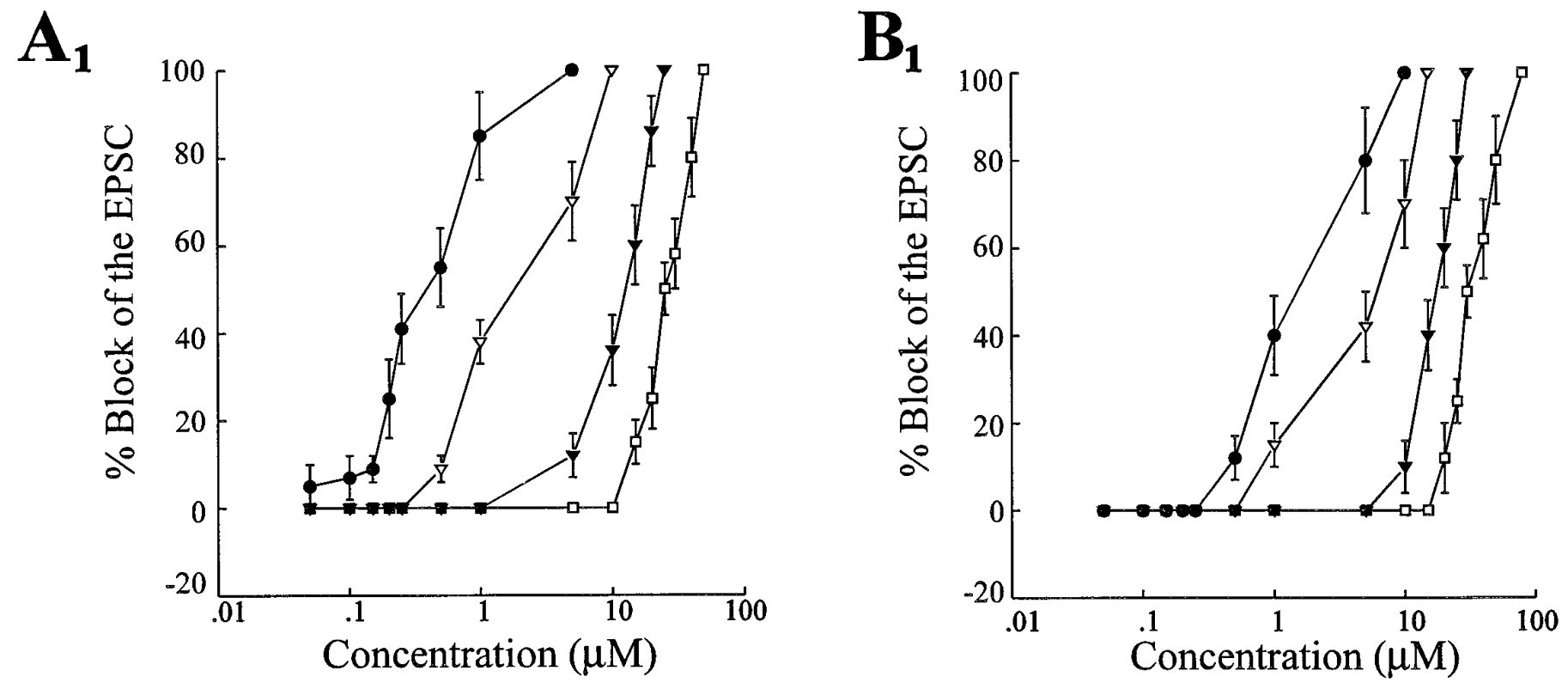

$\mathbf{A}_{2}$

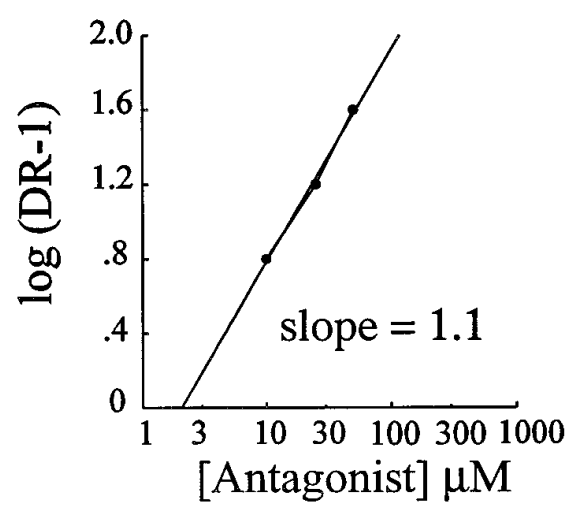

$\mathbf{B}_{2}$

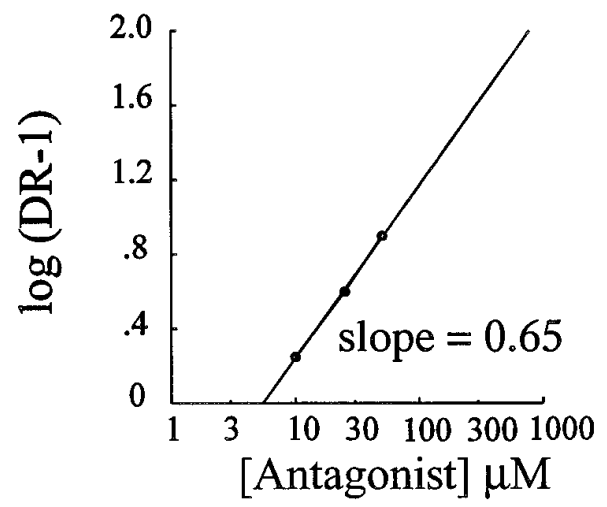

Figure 4. The CGP49823 block of the SP- and CGRP-induced effects show different pharmacological profiles. A1, Dose-response curves for SP alone and in the presence of CGP 49823 at three concentrations $(10,25$, and $50 \mu \mathrm{M})$. The $\mathrm{ED}_{50}$ values of all curves were estimated and used to calculate the dose ratio that was used for Schild plots. $A 2$ shows the Schild plots obtained from these estimates with a slope of 1.1, indicating competitive antagonism between SP and CGP49823 at the NK-1 receptor. B1, CGRP dose-response curves in control (CGRP alone) and in the presence of CGP 49823 under the same conditions as in $A$. B2 shows the Schild plot obtained for the CGRP-CGP49823 interaction. The slope of 0.65 indicates a noncompetitive antagonism.

act on the NK-1 receptor, and when the slice was pretreated with the NK-1 receptor antagonist, we found that it displaced the dose-response curve for SP to the right in a dose-dependent manner. Based on these data, we constructed a Schild plot, which enabled us to conclude that the shift was attributable to a competitive action by the antagonist at the NK-1 receptor.

In contrast to what was seen with SP, CGRP action on the EPSC was not antagonized by the specific rat CGRP antagonist HCGRP. Because there is evidence in the literature for another, yet unidentified CGRP receptor (Dennis et al., 1990), such a receptor could be mediating or contributing to the inhibitory effects of CGRP on synaptic transmission.

The observation that the CGRP-induced inhibition of the evoked EPSC was completely and reversibly blocked by the NK-1 receptor antagonist CGP49823, but not a by specific CGRP receptor antagonist, raises the alternate possibility that the CGRP effect may involve SP which, in turn, acts at NK-1 receptors to inhibit neurotransmitter release. This is supported by the observation that the blockade of CGRP effect by CGP49823 was identical to that of SP at each of six concentrations of the antagonist tested. Nonetheless, when Schild plots were carried out on the CGRP-NK-1 antagonist interaction, the slope of the line was significantly less than 1 , indicating that something other than a competitive interaction with only this NK-1 receptor underlies this antagonism. The complexity of the CGRP-CGP49823 interaction is underlined further by the fact that the $\mathrm{pA}_{2}$ value (estimated as the $x$-axis intercept from Shild plots in Fig. 5) for the antagonist is different from that calculated for an SP-CGP49823 interaction. We cannot at present fully explain this difference, but it does raise the possibility that there are additional subtypes of receptors responsive to these peptides in the PBN.

\section{SP-CGRP interactions}

Additional evidence that the action of CGRP may involve an SP-dependent mechanism comes from our results indicating that the SP inhibitory action on the EPSC can be potentiated by a subthreshold dose of CGRP. Because this action of CGRP potentiating SP can be blocked by the NK-1 antagonist, how might 
A

B
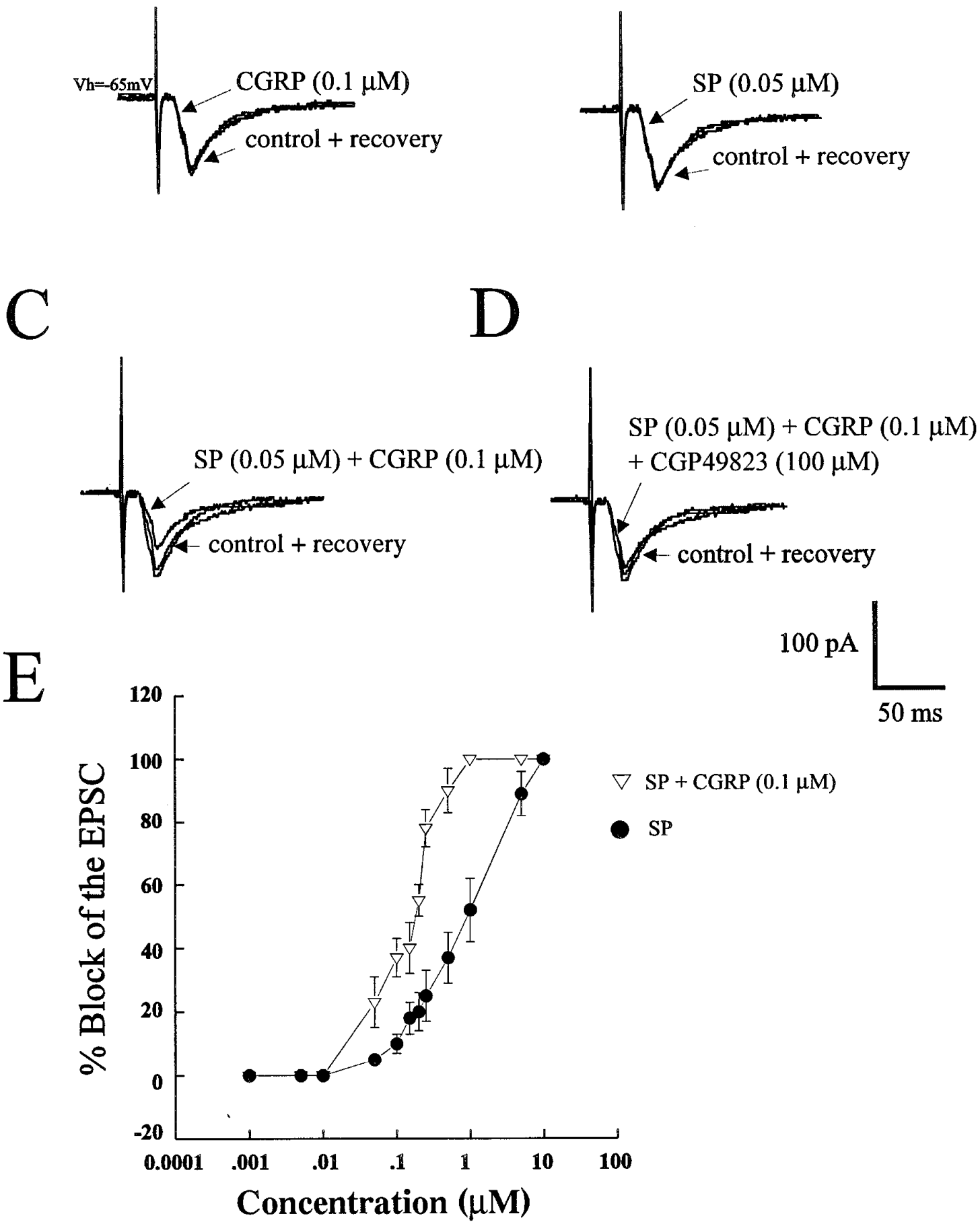

Figure 5. Synergistic interaction between SP and CGRP on the magnitude of the EPSC. $A$ and $B$ illustrate the effect of subthreshold doses of CGRP $(0.1 \mu \mathrm{M})$ and SP $(0.05 \mu \mathrm{M})$, respectively, on the evoked EPSC. $C$, Combined application of both peptides at these concentrations resulted in an attenuation of the EPSC amplitude. D, This synergistic interaction on the evoked EPSC by coapplication of SP and CGRP was reversibly blocked by CGP49823 (100 $\mu \mathrm{M})$. $E$, The synergism between SP and CGRP can be seen at all doses along the dose-response curve for SP $(n=4$ at each dose).

it be working? One possibility is that CGRP stimulates the release of SP by acting at a novel CGRP receptor not susceptible to antagonism by the CGRP antagonist HCGRP. A second possibility is that CGRP may not be acting via a "classical receptor," and a mechanism for its action is suggested by previous findings (Le
Greves et al., 1985; Schaible et al., 1992) that CGRP can interfere with SP degradation by competing with SP for the endopeptidase. This would make more SP available for binding to its receptor and thereby "potentiate" its action. If this, indeed, were the case, the action of CGRP would be dependent on an endogenous, tonic SP 

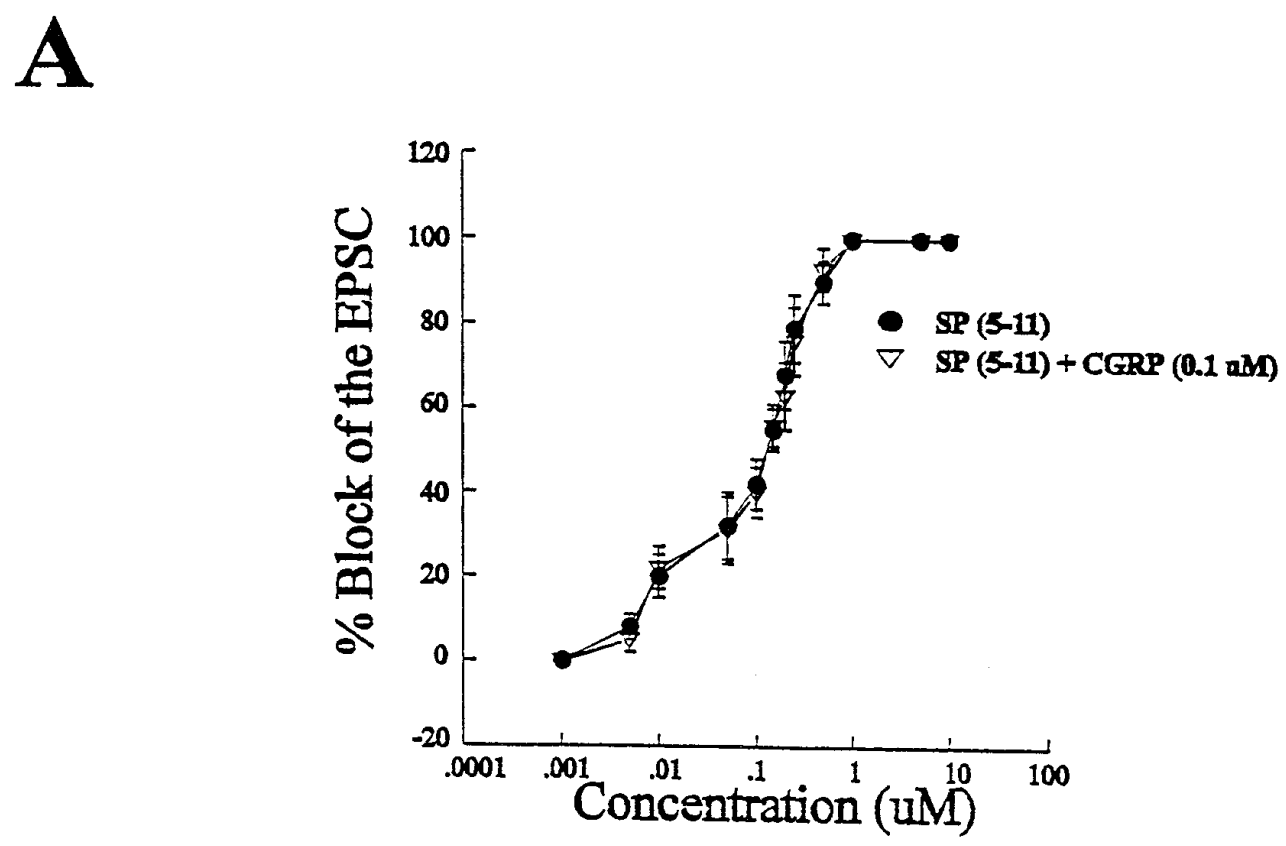

B $_{1}$

$\mathbf{B}_{2}$
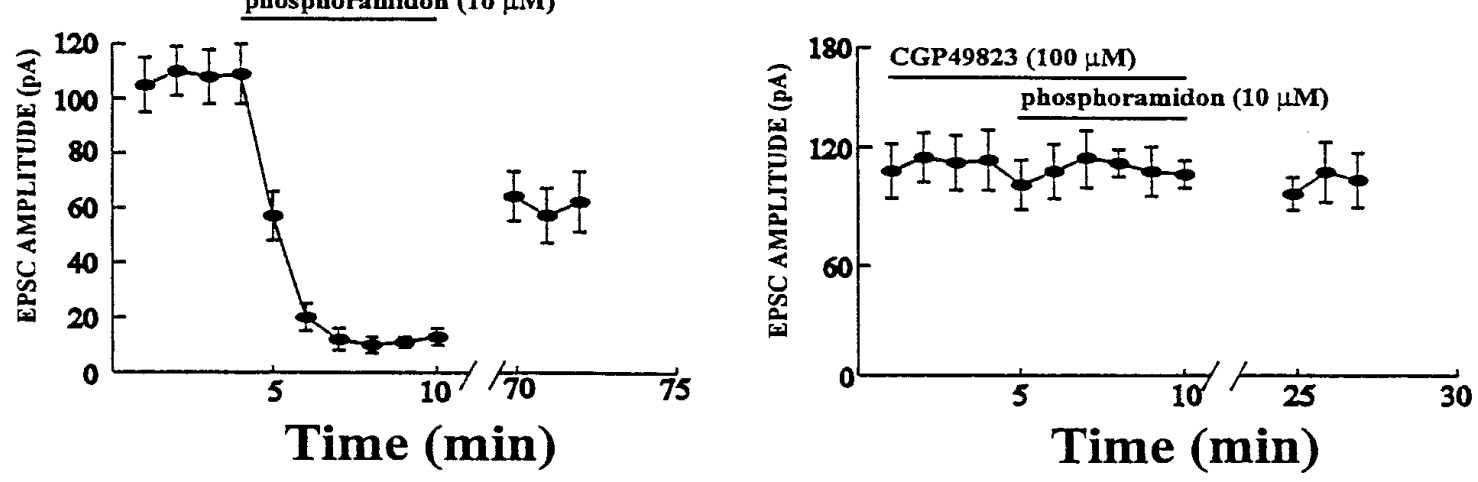

$\mathbf{B}_{3}$
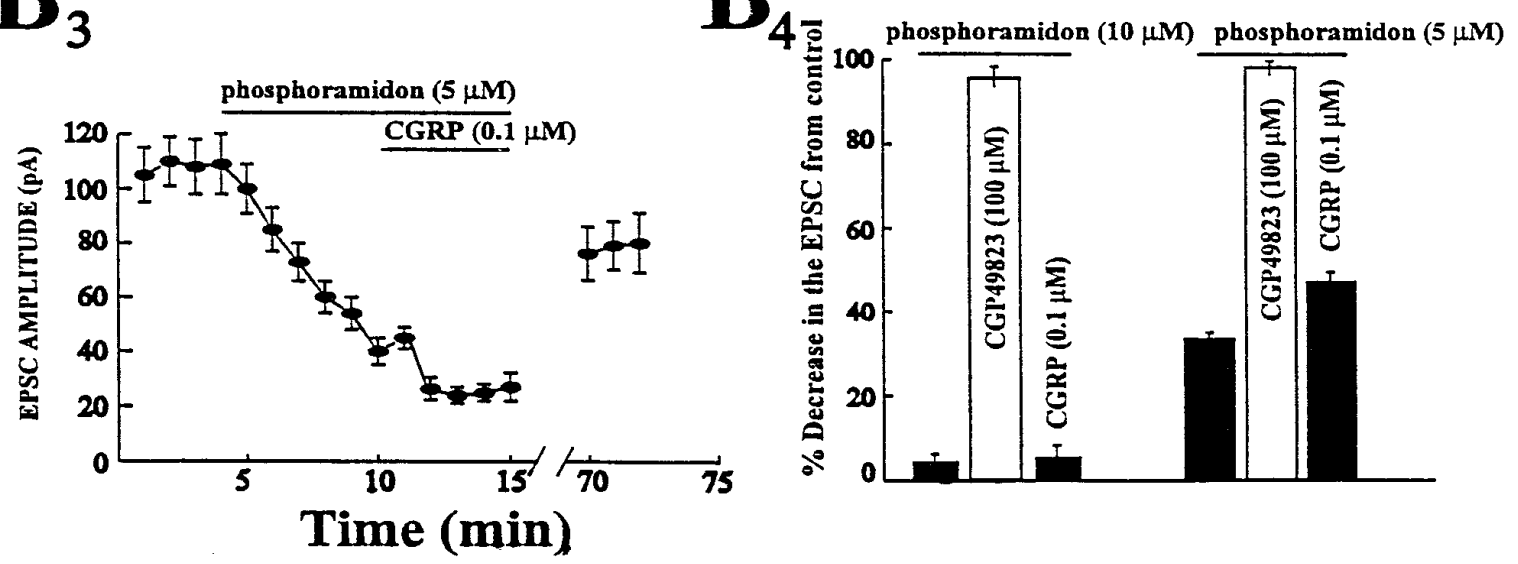

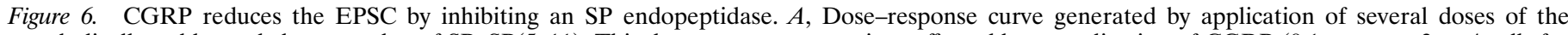

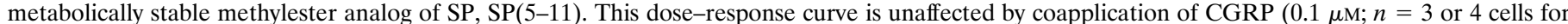

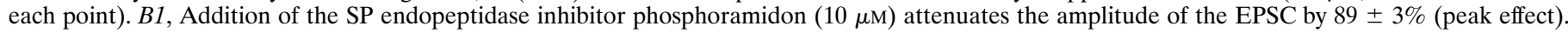

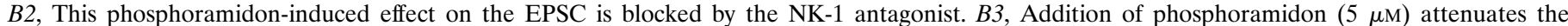

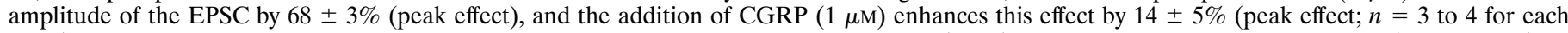

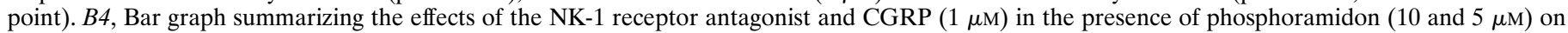
the magnitude of the EPSC. 
release in this nucleus. Our observations that the SP receptor antagonist alone had no effect on the size of the EPSC does not provide any evidence for this scenario. However, an endogenous SP release could still be present but not unmasked by the NK-1 antagonist if a very effective endopeptidase action was constantly removing SP from the synapse. This scenario is supported by our experiments using the endopeptidase inhibitor phosphoramidon. Phosphoramidon $(10 \mu \mathrm{M})$ reduced the amplitude of the EPSC by $89 \pm 3 \%$, an effect that was reversed by the NK-1 receptor antagonist. This indicates that SP is tonically released. Furthermore, in these experiments, CGRP was ineffective in enhancing this effect on the EPSC, indicating that phosphoramidon occluded the CGRP effect. However, when the phosphoramidon concentration was lowered to $5 \mu \mathrm{M}$ and the resulting attenuation of the EPSC was $68 \pm 3 \%$, CGRP was able to enhance the synaptic depression by another $14 \pm 5 \%$. This result strongly suggests that CGRP requires sufficient functional endopeptidase to affect the EPSC on its own or to enhance the SP effect.

\section{Functional considerations}

At the cellular level, we have uncovered evidence for an endogenous release of SP that appears to be functionally ineffective because of the presence of a highly active endopeptidase. If these findings in slice are representative of what is seen in the intact brain, one might question why this seemingly ineffective release of SP should occur. An answer may be found in an understanding of the localization of SP in afferents in the PBN. In the brain and spinal cord, it appears that SP is colocalized with glutamate (Penny et al., 1986; De Biasi and Rustioni, 1988; Copray et al., 1990). While recognizing that release characteristics for amino acids and peptides could be different (Iverfeldt et al., 1989), it is possible that some SP is released concurrently with glutamate. Under basal conditions, it can be appreciated that one might want fidelity of transmission at the glutamergic synapse; concurrent activation of presynaptic SP receptors would interfere with this by reducing the quantity of glutamate released. A highly efficient endopeptidase would prevent this by inactivating the SP coreleased with glutamate (Fig. 7, left). This situation could be different if the afferents are activated at very high frequency, for example, during intense visceral activation; experiments in vivo suggest that under such situations, NMDA receptors underlie the excitatory transmission in the PBN (Saleh and Cechetto, 1994). Given the possible excitotoxic effects of large amounts of glutamate acting at these receptors, it would be advantageous for the coreleased SP to reduce the amount of glutamate released. This could happen if sufficient SP is released to overwhelm the endopeptidase (Fig. 7, right) and thereby permitting SP to bind to the presynaptic receptor. Although such a scenario is speculative, it is open to experimental verification using dialysis monitoring of extracellular glutamate.

The participation of CGRP in this scenario could also be related to a protective action of SP. Cell bodies giving rise to the CGRP-positive afferents in the PBN are thought to lie in the central nucleus of the amygdala (Honkaniemi et al., 1990). There is a population of neurons in the amygdala that are activated under conditions of intense visceral activation (Anton et al., 1991; McKitrick et al., 1993); if there were CGRP-positive cells in this population, release of CGRP in the PBN would add to the effectiveness of the SP in this nucleus by competing for the endopeptidase (Fig. 7, right). Whatever the relevance of this interaction to the physiological state, it points to the care that
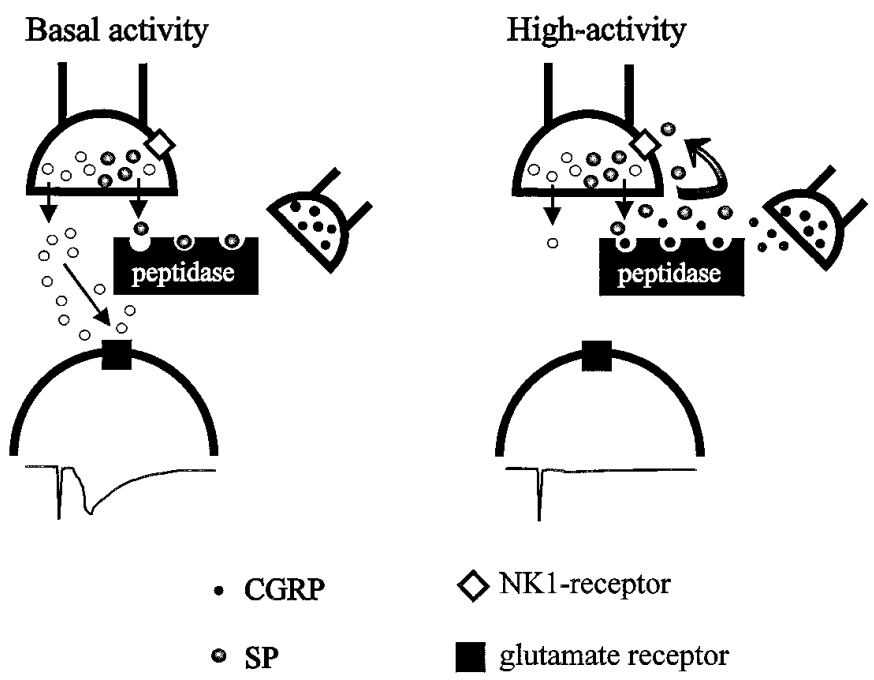

$\diamond$ NK1-receptor
$\square$ glutamate receptor

- glutamate

Figure 7. Schematic diagram illustrating the possible actions of SP and CGRP within the PBN. Left, Under basal conditions, the SP coreleased with glutamate is degraded by an efficient (endo)peptidase, preventing it from reaching its presynaptic NK-1 receptor. Thus, sufficient glutamate is released to produce a postsynaptic response (lower trace). Right, Under conditions of excessive afferent input, sufficient SP is released to overwhelm the peptidase, resulting in activation of its receptor. In addition, CGRP similarly released under conditions of high afferent activity increases the availability of SP by competing with it for sites on the endopeptidase. Thus, glutamate release is more profoundly inhibited, and the postsynaptic response is attenuated (lower trace).

must be taken in interpreting the action of certain peptides on cellular responses.

\section{REFERENCES}

Anton F, Herdegen T, Peppel P, Leah JD (1991) C-fos-like immunoreactivity in rat brainstem neurons following noxious chemical stimulation of the nasal mucosa. Neuroscience 41:629-641.

Aronin N (1983) Substance P. In: Brain peptides (Kruger DT, Brownstein MJ, Martin JB, eds), pp 783-800. New York: Wiley.

Bekkers JM, Stevens CF (1989) NMDA and non-NMDA receptors are co-localized at individual excitatory synapses in cultured rat hippocampus. Nature 341:230-233.

Blanton M, LoTurco J, Kriegstein A (1989) Whole cell recording from neurons in slices of reptilian and mammalian cerebral cortex. J Neurosci Methods 30:203-210.

Chiba Y, Misawa M (1995) Inhibition of neutral endopeptidase increases airway responsiveness to ACh in nonsensitized normal rats. J Appl Physiol 78:394-402.

Copray JC, Ter Horst GJ, Liem RS, van Willigen JD (1990) Neurotransmitters and neuropeptides within the mesencephalic trigeminal nucleus of the rat: an immunohistochemical analysis. Neuroscience 37:399-411.

Dado RJ, Law PY, Loh HH, Elde R (1993) Immunofluorescent identification of a $\gamma$-opioid receptor on primary afferent nerve terminals. NeuroReport 5:341-344.

De Biasi S, Rustioni A (1988) Glutamate and substance P coexist in primary afferent terminals in the superficial laminae of spinal cord. Proc Natl Acad Sci USA 85:7820-7824.

Dennis T, Fournier A, Cadieux A, Pomerleau F, Jolicoeur FB, St. Pierre S, Quirion R (1990) HCGRP $_{8-37}$, a calcitonin gene-related peptide antagonist revealing calcitonin gene-related heterogeneity in brain and periphery. J Pharmacol Exp Ther 254:123-128.

Hamill OP, Marty A, Neher E, Sakmann B, Sigworth F (1989) Improved patch-clamp techniques for high resolution current recording from cells and cell-free membrane patches. Pflügers Arch 391:85-100.

Honkaniemi J, Pelto-Huikko M, Isola J, Rechardt L (1990) Simultaneous localization of calcitonin gene-related peptide and neurotensin in rat central amygdaloid nucleus. Neurosci Lett 113:1-6. 
Iverfeldt K, Serfozo P, Arnesto LD, Bartfai T (1989) Differential release of coexisting neurotransmitters: frequency dependence of the efflux of substance $\mathrm{P}$, thyrotropin releasing hormone and serotonin from tissue slices of rat ventral spinal cord. Acta Physiol Scand 137:63-71.

Kenakin TP (1987) Drug antagonism. In: Pharmacologic analysis of drug-receptor interaction, pp 205-244. New York: Raven.

Korn SJ, Horn R (1989) Influence of sodium-calcium exchange on calcium current run-down and the duration of calcium-dependent chloride currents in pituitary cells, studied with whole cell and perforated patch recording. J Gen Physiol 789-812.

Korn SJ, Marty A, Connor JA, Horn R (1991) Perforated patch recording. J Neurosci Methods 4:264-373.

Kruger L, Mantyh P, Sternini C, Brecha N, Mantyh C (1988) Calcitonin gene-related peptide (CGRP) in the rat central nervous system: patterns of immunoreactivity and receptor binding sites. Brain Res 463:223-244.

Le Greves P, Nyberg F, Terenius L, Hökfelt T (1985) Calcitonin generelated peptide is a potent inhibitor of substance $\mathrm{P}$ degradation. Eur J Pharmacol 115:309-311.

Len WB, Tsou MY, Chan SH, Chan JY (1994) Substance P suppresses the activity of $\alpha 2$-adrenoreceptors of the nucleus reticularis gigantocellularis involved in cardiovascular regulation in the rat. Brain Res 638:227-234.

Livett BG, Kozousek V, Mizobe F, Dean DM (1979) Substance P inhibits nicotinic activation of chromaffin cells. Nature 278:256-257.

Mantyh PW, Hunt SP (1985) Neuropeptides are present in projection neurons at all levels in visceral and taste pathways: from the periphery to the sensory cortex. Brain Res 299:297-311.

McKitrick DJ, Krukoff TL, Calaresu FR (1993) Expression of c-fos protein in rat brain after electrical stimulation of the aortic depressor nerve. Brain Res 196:145-152.

Meriney SD, Gray BD, Pilar GR (1994) Somatostatin-induced inhibition of neuronal calcium current modulated by cGMP-dependent protein kinase. Nature 369:336-339.

Mimeault M, Fournier A, Dumont Y, St. Pierre S, Quirion R (1991) Comparative affinities and antagonistic potencies of various human CGRP fragments on CGRP receptors in brain and periphery. J Pharmacol Exp Ther 258:1084-1090.

Nuki C, Kawasaki H, Takasaki K, Wada A (1994) Pharmacological characterization of presynaptic calcitonin gene-related peptide (CGRP) receptors on CGRP-containing vasodilator nerves in rat mesenteric resistance vessels. J Pharmacol Exp Ther 268:59-64.

Paxinos G, Watson C (1986) The rat brain in stereotaxic coordinates. New York: Academic.

Penny GR, Afsharpour S, Kitai ST (1986) The glutamate decarboxylase-, leucine enkephalin-, methionine enkephalin-, and substance P-immunoreactive neurons in the neostriatum of the rat and cat: evidence for partial population overlap. Neuroscience 17:1011-1045.
Quirion R, Shults CW, Moody TW, Pert CB, Chase TN, O’Donohue TL (1983) Autoradiographic distribution of substance $\mathrm{P}$ receptors in rat central nervous system. Nature 303:714-716.

Rae J, Cooper K, Gates G, Watsky M (1991) Low resistance perforated patch recordings using amphotericin B. J Neurosci Methods 37:15-26.

Ryu PD, Gerber G, Murase K, Randic M (1988) Actions of calcitonin gene-related peptide on rat spinal dorsal horn neurons. Brain Res 441:357-361.

Saleh TM, Cechetto DF (1993) Peptides in the parabrachial nucleus modulate visceral input to the thalamus. Am J Physiol 264:R668-R675.

Saleh TM, Cechetto DF (1994) Neurotransmitters in the parabrachial nucleus mediating visceral input to the thalamus in the rat. Am J Physiol 266:R1287-R1296.

Saleh TM, Cechetto DF (1995) Neurochemical interactions in the parabrachial nucleus mediating visceral inputs to visceral thalamic neurons. Am J Physiol 268:R786-R795.

Saleh TM, Cechetto DF (1996) Modality-related peptide changes in the parabrachial nucleus of the rat. J Comp Neurol, in press.

Schaible HG, Hope PJ, Lang CW, Duggan AW (1992) Calcitonin generelated peptide causes intraspinal spreading of substance $P$ released by peripheral stimulation. J Neurosci 12:750-757.

Schworer H, Schwidt WE, Katsoulis S, Creutzfeldt W (1991) Calcitonin gene-related peptide (CGRP) modulates cholinergic neurotransmission in the small intestine of man, pig, and guinea-pig via presynaptic CGRP receptors. Regul Pept 361:345-358.

Shapiro M, Hille B (1993) Substance P and somatostatin inhibit calcium channels in rat sympathetic neurons via different $G$ protein pathways. Neuron 10:11-20.

Stanley KJ, Otis TS, Mody I (1992) Membrane properties of dentate gyrus granule cells: comparison of sharp microelectrode and whole-cell recordings. J Neurophysiol 67:1346-1358.

Tremblay L, Kenel ML, Desban M, Gauchy C, Glowinski J (1993) Distinct presynaptic control of dopamine release in striatosomal- and matrix-enriched areas of the rat striatum by selective agonists of NK-1, NK-2 and NK-3 tachykinin receptors. Regul Pept 46:124-130.

Urban L, Naeem S, Patel IA, Dray A (1994) Tachykinin induced regulation of excitatory amino acid responses in the rat spinal cord in vitro. Neurosci Lett 168:185-188.

Wiley JW, Gross RA, Macdonald RL (1992) The peptide CGRP increases a high-threshold $\mathrm{Ca}^{2+}$ current in rat nodose neurones via a pertussis toxin-sensitive pathway. J Physiol (Lond) 455:367-381.

Zidichouski JA, Jhamandas JH (1993) Electrophysiological characterization of excitatory amino acid responses in rat lateral parabrachial neurons in vitro. Brain Res 611:313-321.

Zidichouski JA, Easaw JC, Jhamandas JH (1996) Glutamate receptor subtypes mediate excitatory synaptic responses of rat lateral parabrachial neurons. Am J Physiol 270:H1557-H1567. 